\title{
Validity Evidence for the Reduced Version of the Young Parenting Inventory (YPI)
}

\author{
Felipe Valentini ${ }^{1}$ \\ Universidade Salgado de Oliveira, Niterói-RJ, Brazil \\ João Carlos Alchieri \\ Universidade Federal do Rio Grande do Norte, Natal-RN, Brazil \\ Jacob Arie Laros \\ Universidade de Brasília, Brasília-DF, Brazil
}

\begin{abstract}
To gain more insight in family processes, psychometrically tests are required. The present study aimed to adapt a reduced version of the Young Parenting Inventory (YPI) to the Portuguese language and to obtain evidence of its validity. The instrument was administered to a sample of 920 persons (59\% female) with an average age of 21.3 years. Exploratory factor analysis indicated the existence of five factors explaining approximately $45 \%$ of the variance. Confirmatory factor analysis showed fit indices above.80. In comparison with other models, the five factor model showed a better fit to the data. Between the YPI and Familiograma (another test of family processes) moderate correlations were observed. The results of this study suggest satisfactory evidence of the validity for the YPI in Brazil.
\end{abstract}

Keywords: psychometrics, validity, psychological assessment

\section{Evidências de Validade da Versão Reduzida do Inventário de Estilos Parentais de Young}

\begin{abstract}
Resumo: Para aumentar a compreensão dos processos familiares é necessária a construção de instrumentos adequados. O presente estudo teve como objetivo adaptar para o português brasileiro e obter evidências de validade da versão reduzida do Inventário de Estilos Parentais de Young (YPI). O YPI foi respondido por 920 estudantes (59\% sexo feminino), com idade média de 21 anos. As análises fatoriais exploratórias indicaram uma solução de cinco fatores, que explicaram aproximadamente $45 \%$ da variância. As análises confirmatórias apresentaram indicadores de ajuste superiores a 0,80 . Em comparação com outros modelos anteriores, o modelo dos cinco fatores demonstrou melhor ajuste aos dados. Evidenciaramse correlações moderadas entre os fatores do YPI e o teste Familiograma para avaliação da família. Os resultados sugerem que o YPI apresenta evidências de validade para o Brasil.
\end{abstract}

Palavras-chave: psicometria, validade do teste, avaliação psicológica

\section{Evidencias de Validez de la Versión Reducida del Inventario de Estilos Parentales de Young}

\begin{abstract}
Resumen: Para aumentar la comprensión de los procesos de la familia, es necesaria la construcción de instrumentos adecuados. Este estudio tuvo como objetivo la traducción para el portugués y obtención de evidencias de validez de la versión reducida del Inventario de Estilos Parentales de Young (YPI) en Brasil. El YPI fue respondido por 920 estudiantes (59\% mujeres), con edad media de 21 años. Los análisis factoriales exploratorios indicaron una solución de cinco factores que explicaron aproximadamente el $45 \%$ de la varianza. Los análisis confirmatorios mostraron indicadores de ajuste mayores que 0,80. En comparación con modelos anteriores, el modelo de los cinco factores mostró un mejor ajuste a los datos. Entre el YPI e el Familiograma para evaluación de la familia se observaron correlaciones moderadas. Los resultados sugieren que el YPI presenta evidencias de validez en Brasil.
\end{abstract}

Palabras clave: psicometría, validación de test, evaluación psicológica

Family is considered the primary environment where the child participates and also represents an important mediation role among the primary contact of the child with the world. In this context, current researches have been emphasizing family and its influence in the normal, pathological, social, emotional and cognitive development of a child and adolescent (Baptista \& Oliveira, 2004; Cecconello, De Antoni, \& Koller, 2003; Spera, 2005).

\footnotetext{
1 Correspondence address:

Felipe Valentini. Laboratório META, Sala A1-061/4. Universidade de Brasília - Campus Universitário Darcy Ribeiro. CEP 70910-900. Brasília-DF, Brazil. E-mail: valentini.felipe@gmail.com
}

Previous studies about family identified two interacting dimensions between parents and children: the parenting styles and the parenting practices. The parenting practices refer to the parenting behavior, of specific contents, that aims for the child and adolescent socialization. In a broad view, the parenting styles refer to the global characteristics of interactions between parents and child, which generate emotional environment. On basis of this emotional environment parenting behavior is expressed. The parenting styles, therefore, comprise the parenting practices and other aspects of parent-child interaction, such as voice tone, body language and attention (Baumrind, 1966; Cecconello et 
al., 2003; Darling \& Steinberg, 1993; Maccoby \& Martin, 1983; Steinberg, 2001). In order to adequate to the theme of this study, the following discussions will be restricted to parenting styles.

Researches have been associating parenting styles to pathological characteristics of child, such as alimentary disorders, overweight, drug abuse, anxiety, depression, suicidal behavior and personality maladjusted traits (Cohen, Sade, Benarroch, Pollak, \& Gross-Tsur, 2008; Flouri, 2005). However, other studies lead to relations between styles and the positive aspects of development such as resilience, optimism, life quality, healthy nutrition and academic achievement (Weber, Brandenburg, \& Viezzer, 2003; Zimmermann, Eisemann, \& Fleck, 2008).

The investigations related to parenting styles and psychosocial aspects lead to a theory advance, mainly after the second half of past century. In this context, the psychopathologies, preventive measures, and the relation between these aspects with family have been highlighted in literature. Nevertheless, no one has proposed a clinical model of comprehension of parental styles until 1990. Therefore, the construction of such a model could amplify the discussion of the theme since it would include the aspects related to the development of psychopathologies. The model of parenting styles by Young (Young, 2003; Young, Klosko, \& Weishaar, 2003) fulfilled this lacuna.

The Young's clinical model (2003) comprises 18 parenting styles, distributed over five domains. The first domain is named Disconnection and Rejection and concerns the cold, abusive and unpredictable families. The second is named Impaired Autonomy and Performance, and refers to overprotective families with difficulties to maintain confidence in their children when they are outside the family environment. The third domain, Impaired Limits, is related to familiar characteristics of permissiveness, difficulty of establishing limits and discipline, and with a lack of secure orientation. The fourth domain, Other-Directedness, is observed in families that consider the social acceptance status more important than their own feelings. Finally, the Overvigilance and Inhibition domain is characterized by grim, demand and punishment, being typical in families more concerned with avoiding mistakes than stimulating pleasurable aspects (Van Vlierberghe, Timbremont, Braet, \& Basile, 2007; Young, 2003; Young et al., 2003).

To evaluate the styles and domains, Young has developed the Young Parenting Inventory - YPI (Young, 1999). This inventory, originally in English, was composed of 72 items distributed over 18 factors. It is important to note that this structure proposed by Young is a theoretical model and was not empirically tested by the authors. Although the literature of the schema is not vast, some validation studies of the YPI, performed by independent researchers, were found, as well as associations between parenting styles and psychopathology (Hinrichsen, Sheffield, \& Waller, 2007; Noie, Farid, Fata, \& Ashoori, 2010; Van Vlierberghe et al., 2007).

Referring to the psychometric characteristics of the YPI, a preliminary validation research of this instrument was published (Sheffield, Waller, Emanuelli, Murray, \& Meyer, 2005). The results showed a solution of nine factors of the 18 theoretically proposed factors. Most items showed factor loadings above .60. The reliability was verified by internal consistency and the retest method, whose indicators were above .60. The researchers also found significant associations between parenting styles and schemas, and have concluded that after adjustments, the instrument has showed acceptable psychometric properties. Sheffield, Waller, Emanuelli e Murray (2006) also studied the criterion validity of reduced version of YPI. This version is composed of 37 items (in other words, 35 items less than the original) selected by exploratory factor analysis. The study highlighted the roles of punitive, pessimist and controlling parenting styles to predict psychopathological cases. The results, in general, also have indicated that the criterion validity of the instrument is acceptable. However, the structure presented by the authors is long (nine specific factors) and does not consider the possibility to assess wider dimensions that could sustain the specific dimensions. This limitation hampers a proper analysis and an interpretation of the results.

Although Young's clinical inventory might bring up information about the parenting styles and consequently contribute to the comprehension of a child and adolescence development, the YPI is not yet valid for use in Brazil. In this context, researchers have been reporting the importance of a validation of the instrument for the Brazilian culture (Noronha \& Alchieri, 2002; Noronha, \& Vendramini, 2003). Furthermore, the YPI structures presented in previously studies are long and need evidence to be confirmed. The present research seeks to fulfill this lacuna. The objective of this study is to adapt the YPI for Brazilian Portuguese and to obtain evidence of content and construct validity. Specifically, the construct validity of the instrument will be assessed by exploratory and confirmatory factor analysis, as well by convergent validity with the Familiogram test. Considering that the original YPI presents 18 factors and that the study of Sheffield et al. (2005) presents nine factors, it is expected to rearrange the inventory in a more parsimonious factor structure. Besides, it is also expected moderate relations between the YPI and Familiogram.

\section{Method}

\section{Participants}

Given the objective of validation of the YPI, the sample data was collected by convenience. Therefore, the instruments were applied in a not clinical sample of 920 students (59.3\% female), with ages between 16 and 49 years old $(M=21.3 ; S D=6.1)$, the majority of them being single $(64.6 \%)$. Considering the language specifications adopted in YPI, the participants were included in the sample only if their level of education was equal or superior to the second year of high school. Approximately 5\% of the invited persons did not consent in participating, therefore they did not participate in the study. The data collection took place in universities and schools of the following cities: Natal $(67.9 \%)$, Petrolina-PE (11.3\%), Brasilia-DF (6.6\%), São Leopoldo-RS (4\%) and in the metropolitan region of Porto Alegre-RS (10.2\%). 


\section{Instruments}

Regarding parenting styles, the participants were assessed by the YPI. The original version of the instrument assesses 18 parenting styles, maternal and paternal, by 72 items, distributed over five domains. In each item the person evaluates how well that sentence describes his father and mother, separately, during childhood. This task is performed by a Likert scale of six points. Thereby, scores of paternal style and maternal style are separately calculated for each one of the 18 dimensions.

In the present research the YPI was adapted to the Brazilian Portuguese language. Therefore, its factorial configuration and distribution of the items were modified. Likert scale of six points - which translation and comprehension in Portuguese language is difficult - was also modified by a committee of three specialists in psychological assessment. The final version of the scale was composed of five anchor points, ranging from "does not describe anything" to "describes perfectly". It is important to observe that the version of five anchor points, instead of the six points version, allows the participant choose a central value ("describe more or less"). Furthermore, 23 items were excluded from the original version. Such alterations were necessary for a satisfactory factor solution, but the alterations were done in such a manner to maintain as much as possible the characteristics of the original instrument.

In order to verify the convergent validity of YPI, the subjects were also assessed by the Familiogram (FG). The FG was developed by Teodoro (2006) in order to assess the family dyads through two dimensions: Affectivity and Family Conflict. The author defines affectivity as the set of positive emotions of the relationship between dyads. On the other hand, the negative feelings inside the family (source of stress and aggressiveness) are understood as part of the construct of Family Conflict. The FG consists of a set of 22 adjectives. The participant is asked to evaluate how well each of these adjectives describes the relationship between the dyads. This task is performed using a Likert scale of five points. The author has presented evidence of a two-factor structure with reliability coefficients (Cronbach's Alpha) of .87 and .97.

\section{Procedure}

Data collection. O YPI was adapted to the Portuguese language by the back translation method (Hambleton, 1996). This stage aimed to evaluate the equivalence of items between the original inventory and the retranslated one. Firstly, four bilingual persons translated the instrument from English to Portuguese. Five judges and one specialized committee evaluated the translations and consolidated one preliminary version of the inventory. Afterward, this version was back translated to English by a bilingual professional who did not know the original scale.

The content validity was performed by judges. Five judges evaluated all items of preliminary version, considering the language accuracy, theoretical relevance and the most appropriate theoretical construct. The agreement between the judges was evaluated by the calculation of the Content
Validity Coefficient (CVC) (Hernández-Nieto, 2002) and Cohen's Kappa coefficient.

After adjustments, the preliminary version of the YPI was administered by properly trained psychologists. The tests were collectively administered in classrooms. The participants were voluntary and had signed two copies of Statement of Consent, holding a copy. The parents of participants under 18 years old were also asked to sign the Statement of Consent.

Data analysis. The construct validity of the YPI was assessed using exploratory and confirmatory factor analysis. With regard to confirmatory analysis, the following goodness of fit indices were considered: (1) the critical ratio between chi-square and degrees of freedom; (2) the Goodness-of-Fit Index (GFI); (3) the Tucker-Lewis Index (TLI); and (4) the Root Mean Square Error Approximation (RMSEA) (Byrne, 2010; Pilati \& Laros, 2007). The indices GFI and TLI above .80 and the RMSEA under .10 were considered as minimally adequate. Reliability of YPI scores was explored by Cronbach's alpha, adopting the .70 value as indicator of adequate internal consistency. The convergent validity of the YPI was explored by correlations between YPI and Familiogram (FG). Moderate correlations $(r>.30)$ were expected between the scores of these two instruments. It must be noted that the FG was applied only in a subsample of $20 \%$ of the total sample. The subsample was adopted to reduce the duration of data collection and the amount of research costs.

\section{Results}

After the adaptation of the preliminary version of the YPI, five judges analyzed the content of the inventory. Over $90 \%$ of its items presented a content validity coefficient (CVC) above .90 regarding to language accuracy and theoretical relevance. Nevertheless, two items were evaluated as items with poor language accuracy $(\mathrm{CVC}<.80)$ and one item poor in theoretical relevance $(\mathrm{CVC}=.77)$. These items were improved by a committee of three experts.

The judges also indicated the most appropriate theoretical dimension for each item, considering the five domains of Young's theory. The agreement analysis between the theoretical dimensions and indications performed by the judges was realized on the 66 items that had an internal concordance between the judges equal to or above $60 \%$. The indications of the judges of 52 items were consistent with the theoretical dimensions proposed by the original YPI and while the remaining 14 items did not correspond to the original theoretical dimension. The average Kappa coefficient for agreement between the indications of the judges and the theoretical dimensions was .51 (all coefficients presented $p<.05$ ).

Preliminary factor analyses were performed to verify the need of item exclusion. The following criteria for item exclusion were adopted: (1) factor loading under .30; (2) commonalities under .25; (3) incongruence of the factor structure between maternal and paternal scale; and (4) factor loadings above .30 on more than one factor. Using these criteria, 23 items were excluded.

In the second factor analysis, the factorability of the matrix was verified. The results supported the use of the factor analysis, 
once the KMO was 93 both for the maternal as the paternal scales. Thus, the principal components analysis (PC) was conducted. The original YPI structure and the parallel analysis (O'Connor, 2000) were considered to determine how many factors needed to be extracted. The results showed that the empirical eigenvalues of the fifth factor were greater than the random eigenvalues (paternal scale: empiric $=1.57$, random $=1.34$; maternal scale: empiric $=1.50$, random $=1.34$ ). However, for the sixth factor, the random eigenvalues were greater than the empirical eigenvalues (paternal scale: empirical $=1.22$, random $=1.32$; maternal scale: empirical $=1.26$, random $=1.31$ ). Thus, the parallel analysis indicated the extraction of five factors. The five factor solution explained $45.1 \%$ of the variance of the maternal scale and $47.6 \%$ of the paternal scale. In order to improve the interpretation of the factors, an oblique rotation was performed using the Direct Oblimin method, considering the correlations between the factors.

Table 1

Extracted Factors of the Young Parenting Inventory for the Maternal Scale $(n=917)$ and Paternal Scale $(n=878)$

\begin{tabular}{lccccc}
\hline F & Scale & $\begin{array}{c}\text { Number of } \\
\text { items }\end{array}$ & Eigenvalue & $\begin{array}{c}\text { Interval of factor } \\
\text { loadings }\end{array}$ & $\alpha$ \\
\hline I & Maternal & 18 & 11.19 & $.32-.76$ & .89 \\
& Paternal & 18 & 11.31 & $.30-.72$ & .90 \\
II & Maternal & 9 & 1.88 & $.38-.78$ & .85 \\
& Paternal & 9 & 5.69 & $.44-.80$ & .88 \\
III & Maternal & 11 & 2.79 & $.39-.78$ & .83 \\
& Paternal & 11 & 2.65 & $.36-.77$ & .85 \\
IV & Maternal & 6 & 4.75 & $.53-.76$ & .78 \\
& Paternal & 6 & 2.11 & $.59-.80$ & .79 \\
V & Maternal & 5 & 1.50 & $.42-.68$ & .66 \\
& Paternal & 5 & 1.57 & $.49-.68$ & .71 \\
\hline
\end{tabular}

Note. The eigenvalues refer to the values before the rotation of the factors. The factor loadings refer to the values after the rotation of the factors.
Table 1 summarizes the results of the factor analysis and the reliability analysis. All eigenvalues were superior to one and the factor loadings were all above .30. All factors showed minimally adequate coefficients of internal consistency, except for the fifth factor of the maternal scale with a Cronbach's alpha of .66.

In order to define the main characteristics of each factor, the similarity of the item contents was observed. Establishing the main characteristics of each factor contributed to interpretation of the factor scores. The main characteristics of each factor are shown in Table 2.

By comparing the present model with the original, it was observed that two factors did not confirm their original structure. The factor Disconnection and Rejection, originally proposed, was divided into two: Factor I (Disconnection and Rejection) and Factor II (Affectivity and Emotional Stability). It is important to note that the greater part of items of the Affectivity and Emotional Stability factor were inverted in the original version (therefore, it had negative factor loadings). Besides, the Overvigilance and Other-Directedness factors theoretically proposed as two separated dimensions were joined into a single factor in this present research.

In order to verify the relations between the factors, an analysis of the Pearson correlations between the factors was performed. Although some of these correlations were low, approximately $50 \%$ of them were at least moderate $(r>.30)$. It is noteworthy that correlations with Factor I were largely exceeding .50.

After exploratory analysis, a confirmatory factor analyzes was performed using the maximum likelihood method of estimation (ML). This analysis included 49 YPI items (observed variables), as well as five factors (latent variables) indicated by previously realized exploratory factor analysis. Considering that the data did not fit the assumption of multivariate normality (critical ratio of the Mardia coefficient $>5$ ) the bootstrap method was used. Hereby, the coefficients were estimated based on 200 bootstrap resamples.

Table 2

Example of Items and Factor Characteristics

\begin{tabular}{|c|c|c|}
\hline Factor & Examples of Items & Parenting Characteristics \\
\hline $\begin{array}{l}\text { I-Disconnection and } \\
\text { Rejection }\end{array}$ & $\begin{array}{l}\text { Didn't really want me to succeed. } \\
\text { Expected me to be a failure in life. } \\
\text { Made me feel unloved or rejected. }\end{array}$ & $\begin{array}{l}\text { Defectives, cold, abusive and rejecting. The items also } \\
\text { point to disrespect and lack of emotional stability. }\end{array}$ \\
\hline $\begin{array}{l}\text { II - Affectivity and } \\
\text { Emotional Stability }\end{array}$ & $\begin{array}{c}\text { Listened to me, understood me, shared feelings with me. } \\
\text { Was warm and physically affectionate. } \\
\text { Gave me helpful guidance and direction. }\end{array}$ & $\begin{array}{l}\text { Affective, comprehensive, counselors, comprehend } \\
\text { the child needs of acceptance, affection, and emotional } \\
\text { stability. }\end{array}$ \\
\hline $\begin{array}{l}\text { III - Overvigilance } \\
\text { and Other- } \\
\text { Directedness }\end{array}$ & $\begin{array}{l}\text { Was demanding; expected to get things his/her way. } \\
\text { Had to have everything under control. } \\
\text { Was concerned with social status and appearance. } \\
\text { Placed strong emphasis on success and competition. }\end{array}$ & $\begin{array}{l}\text { Impose strict rules and they are vigilantes regarding } \\
\text { their rules execution. Parents concerned about the other } \\
\text { people's opinion about performance and social status. }\end{array}$ \\
\hline $\begin{array}{l}\text { IV - Overprotection } \\
\text { and Impaired } \\
\text { Autonomy }\end{array}$ & $\begin{array}{l}\text { Overprotected me. } \\
\text { Worried excessively that I would get sick. } \\
\text { Did too many things for me instead of letting me do } \\
\text { things on my own. }\end{array}$ & $\begin{array}{l}\text { Overprotect the child and adolescent and had } \\
\text { difficulties of maintaining the child's confidence and } \\
\text { autonomy when outside the family environment. Over } \\
\text { concerned about disease and damage. }\end{array}$ \\
\hline V - Impaired Limits & $\begin{array}{l}\text { Set few rules or responsibilities for me. } \\
\text { Provided very little discipline or structure for me. } \\
\text { Didn't teach me that I had responsibilities to other people. }\end{array}$ & $\begin{array}{l}\text { Parents have difficulty of establishing rules, appropriate } \\
\text { limits, and safe guidance. }\end{array}$ \\
\hline
\end{tabular}


Seeking a good fit to the data, three covariances between errors terms associated with items with similar content were estimated. The bias values calculated by bootstrap were less than .01 , which points to the tendency that the estimated coefficients were not overly impacted by the violation of the assumption of multivariate normality. The bootstrap unstandardized coefficients showed a critical ratio above 1.96, showing that the estimated parameters are significantly distinct of 0 . Besides, the standardized coefficients ranged from .27 to .85 for the maternal scale and from .33 to .86 for the paternal scale. Furthermore, $65 \%$ of the standardized coefficients of the maternal scale and $67 \%$ of the paternal scale presented values above .50 .

Furthermore, the stability of the five factor structure over different subsamples was investigated. Thus, the total sample was divided into two random groups and these were compared by invariance analysis, in the context of structural equation modeling. Four models were tested by fixing the following elements in the subsamples: The factor structure (model 1); the factor structure and the factor loadings (model 2); the factor structure and the intercepts (model 3); and the factor structure, factor loadings, the intercepts and the residual variance (model 4). The models were compared using the chisquare, and the TLI and CFI goodness of fit indices.

Table 3 presents the results of the invariance analysis. The chi-square difference was statistically significant only between models 3 and 4. The maximal change of the TLI and CFI values was .008 . These results indicate that the goodness of fit indices did not change with the restriction imposed for the two random subsamples groups. The results suggest that the five factor structure was stable in distinct subsamples or, in other words, that there is evidence of an invariant factor structure.

The five factor model was also compared to the theoretical model proposed by Young (2003) and the model presented in the article of Sheffield et al. (2005). This procedure aimed to explore whether the model fit of the present research was better than the model fit in previous research.

Table 4 presents the goodness of fit indices of the models. The five factor model proposed in this research did not show a perfect fit to the data. However, the fit indices suggested a minimal accepted model with GFI and TLI values above .80 and a RMSEA value under .08. Moreover, the five factor model presented a better fit than the models of 17 and 9 factors. The results indicated that the misfit of the five factor model, measured by chi-square, was significantly smaller $(p<.05)$ than that misfit of the models of 9 and 17 factors. Furthermore, the GFI and TLI indices of the five factor model were considerably higher than the previous models.

After consolidation of the factor structure of the YPI, the correlations between the YPI and the dimensions of Familiogram (FG) were studied, in order to acquire evidence of the convergent validity of the YPI. The results of the Pearson correlations are presented in Table 5.

Table 3

Analysis of Parameter Invariance Between Random Subsamples

\begin{tabular}{|c|c|c|c|c|c|}
\hline Model & $\chi^{2}(\mathrm{df})$ & $\Delta \chi^{2}(\Delta \mathrm{df})$ & $\mathrm{CR}$ & TLI & CFI \\
\hline \multicolumn{6}{|l|}{ Maternal } \\
\hline Model 1 & $5,504.6(2228)$ & - & - & .799 & .810 \\
\hline Model 2 & $5,574.9(2277)$ & 70.3 (49) & 1.43 & .802 & .808 \\
\hline Model 3 & $5,629.2(2326)$ & $54.3(49)$ & 1.11 & .806 & .808 \\
\hline Model 4 & $5,758.2(2378)$ & $129(52)$ & 2.48 & .806 & .804 \\
\hline \multicolumn{6}{|l|}{ Paternal } \\
\hline Model 1 & $6,103.4(2228)$ & - & - & .782 & .794 \\
\hline Model 2 & $6,188.8(2277)$ & 85.4 (49) & 1.74 & .785 & .792 \\
\hline Model 3 & $6,237.5(2326)$ & 48.7 (49) & .99 & .790 & .792 \\
\hline Model 4 & $6,376.7(2378)$ & $139.2(52)$ & 2.68 & .790 & .787 \\
\hline
\end{tabular}

Note. Model 1 = Five factors fixed; Model 2 =Additionally the factor loadings were fixed; Model 3 =Additionally the intercepts were fixed; Model $4=$ Additionally the residual variance was fixed; $\Delta \chi^{2}(\Delta \mathrm{df})=$ Difference between the chi-square and difference between the degrees of freedom for the comparison of the model with the previous model; $\mathrm{CR}=$ Critical Ratio for $\Delta \chi^{2} / \Delta \mathrm{df}$.

Table 4

Confirmatory Factorial Analysis of the 17 Factor Model, the 9 Factor Model, and the 5 Factor Model

\begin{tabular}{lcccccccc}
\hline Model & Scale & $\chi^{2}(\mathrm{df})$ & $\chi^{2} / \mathrm{df}$ & $\Delta \chi^{2}(\Delta \mathrm{df})$ & $\mathrm{CR}$ & GFI & TLI & RMSEA (CI) \\
\hline \multirow{2}{*}{17 factors (72 items) } & Maternal & $16,039.3(2484)$ & 6.46 & - & & .55 & .41 & $.08(.07-.08)$ \\
& Paternal & $17,610.9(2484)$ & 7.09 & - & & .49 & .38 & $.08(.07-.08)$ \\
9 factors (37 items) & Maternal & $5,694.7(629)$ & 9.05 & $10,344.6(1855)$ & 5.58 & .67 & .50 & $.09(.09-.10)$ \\
& Paternal & $6,251.1(629)$ & 9.94 & $11,359.8(1855)$ & 6.12 & .64 & .49 & $.10(.09-.10)$ \\
5 factors (49 items) & Maternal & $4,076.8(1114)$ & 3.66 & $1,617.9(485)$ & 3.34 & .83 & .82 & $.05(.05-.06)$ \\
& Paternal & $4,461.1(1114)$ & 4.01 & $1,790.0(485)$ & 3.69 & .81 & .81 & $.06(.05-.06)$ \\
\hline
\end{tabular}

Note. 17 factors $=$ theoretical model proposed by Young (1999), composed of 17 first order factors and five second order factors; 9 factors $=$ empirical model proposed by Sheffield et al. (2006), composed of nine orthogonal factors; 5 factors $=$ empirical model proposed by the present research, composed of five oblique factors; $\Delta \chi^{2}(\Delta \mathrm{df})=$ Difference between the chi-square and difference between the degrees of freedom for the comparison of the model with the previous model; $\mathrm{CR}=$ Critical ratio for $\Delta \chi^{2} / \Delta \mathrm{df} ; \mathrm{CI}=90 \%$ Confidence Interval of the RMSEA values. 
Table 5

Correlations Between the Five Factors of the Young Parenting Inventory (YPI) and the Two Factors of the Familiogram (FG) for Participant-Mother Dyad $(n=195)$ and Participant-Father Dyad $(n=188)$

\begin{tabular}{|c|c|c|c|c|}
\hline & \multicolumn{4}{|c|}{ Familiogram Test } \\
\hline & \multicolumn{2}{|c|}{ Participant-Mother Dyad } & \multicolumn{2}{|c|}{ Participant-Father Dyad } \\
\hline & Affect $(r)$ & $\operatorname{Conf}(r)$ & Affect $(r)$ & $\operatorname{Conf}(r)$ \\
\hline \multicolumn{5}{|c|}{ YPI Maternal } \\
\hline F I & $-.48 *$ & $.59^{*}$ & $-.17^{*}$ & $.20^{*}$ \\
\hline F II & $.69^{*}$ & $-.43^{*}$ & $.19^{*}$ & $-.15^{*}$ \\
\hline F III & $-.16^{*}$ & $.42 *$ & -.01 & $.19^{*}$ \\
\hline F IV & $.16^{*}$ & .12 & .02 & .09 \\
\hline F V & $-.29 *$ & $.28 *$ & -.11 & .11 \\
\hline \multicolumn{5}{|c|}{ YPI Paternal } \\
\hline F I & $-.26^{*}$ & $.38^{*}$ & $-.43 *$ & $.58^{*}$ \\
\hline F II & $.23 *$ & -.14 & $.70^{*}$ & $-.44^{*}$ \\
\hline F III & .06 & $.16^{*}$ & -.12 & $.45^{*}$ \\
\hline F IV & .05 & $.15^{*}$ & $.40^{*}$ & -.11 \\
\hline F V & $-.15^{*}$ & $.23 *$ & $-.29 *$ & $.22 *$ \\
\hline
\end{tabular}

Note. Affect $=$ Affectivity; Conf $=$ Family Conflict; F I=Disconnection and Rejection; F II = Affectivity and Emotional Stability; F III = Overvigilance and Other-Directedness; F IV $=$ Overprotection and Impaired Autonomy; F V = Impaired Limits. $* p<.05$.

It is possible to observe in Table 5 that most of the correlations were statistically significant, although some were weak. Stronger relations were observed between the Affectivity and Emotional Stability factor of the YPI and the Affectivity dimension of the FG (for mother $r=.68$; and for father, $r=.70$ ). Moreover, the Disconnection and Rejection factor of the YPI showed a moderate correlation with the Conflict dimension of the FG (for mother, $r=.59$; and for father, $r=.58$ ).

\section{Discussion}

The present study verified evidence of the content and construct validity of the reduced version of the YPI for the Brazilian context. Although the Young's clinical model has been studied in other countries, the YPI is not yet available for use in Brazil. The present research results indicate that, in general, the five domain model is an adequate model to be used in Brazilian research.

Referring to the content validity of the YPI, the use of a committee formed by three experts is highlighted. It allowed the consolidation of a preliminary version of the inventory performed by more than one person, reducing biases. The content validity coefficient was adequate for most items, therefore indicating the relevance of the use of the preliminary version into the successive steps of the present research.

The indications by the judges to the most appropriate dimension for each item were not consistent with the original theoretical propose for 14 items. Besides, it should be noted that the average Kappa coefficient, although statistically significant, only indicates a median agreement between the original theory and the evaluation of the judges (experts).
The results pointed to problems between item construction and their relation with the original theory.

Concerning to the data collection, a primary limitation for this research is the sample composition by convenience. Moreover, all participants were students. In this sense, new studies on representative samples need to be performed to confirm and improve the proposed structure. Another suggestion for future research is to investigate the instrument in clinical samples.

The criteria for the elimination of the items could not be conservatory, under penalty of changing the structure of the model too much. Nevertheless, 23 items were excluded. The main difficulty was the occurrence of factor loadings of items on distinct factors of the maternal and paternal scales. A possible solution would be to maintain the different structures for the maternal and paternal scales. The Sheffield et al. (2005) study adopted this strategy. However, distinct scales hamper the comparison between scales in future researches and their clinical use. Thus, it was decided to maintain a unique structure for both scales with the elimination of some items as a consequence.

The coefficients of the factor exploratory analysis were estimated using the principal components method (PC). Other estimation methods were used such as maximum likelihood (ML) and principal axis factoring analysis (PAF). However results of these other methods were difficult to interpret, besides the problem of factor loadings on different factors in the maternal and the paternal scale became worse. Thus principal components method was adopted. This method has the tendency to overestimate factor loadings and therefore the commonalities and eigenvalues which decrease the control of type II error. These aspects obviously decrease the model stability. However, it is necessary to note that the stability of a model, in psychometric, can also be demonstrated by successive studies that adopt distinct samples and methods (Pasquali, 2003). Therefore, new studies need to be undertaken in order to test and refine the model proposed in the present research. In that order, replicate the present research is important after reviewing the excluded items, as well as those items that showed the lower factor loadings.

The results of factor analysis also indicated that some items migrated between factors. For example, the item 34 ('made me feel that I couldn't trust on my own decisions or my personal judgments') was theoretically supposed to assess the Impaired Autonomy and Performance factor, however the item loaded on Disconnection and Rejection factor. It is noteworthy that in the Sheffield et al. (2005) study the majority of the items also migrated to different dimensions than those originally proposed. Besides, the factor structure of the YPI was also modified.

In other words, the theoretical structure proposed by Young (2003) was broadly revised. However, ongoing scientific research, both national and international, on Young's theory needs to be performed. Especially research with persons which present some psychopathology is indicated, once the YPI instrument was originally constructed to assess the parenting styles of clinical samples. 
The factors in this study presented correlations between themselves. These results were expected, once their content is somewhat similar. For example, the content of defectiveness and abandonment, measured by Factor I, is contrary to the content of affection and tenderness, measured by Factor II. The correlations between the factors also support the use of Direct Oblimin rotation method in exploratory factor analysis.

With regard to the interpretation of the factors, the evaluation of cold, rejective and abusive parents (Factor I) is antagonist to the characteristics of affective, comprehensive and supportive parents (Factor II). Such characteristics are consistent with the parental responsiveness dimension proposed by the classical model of Maccoby and Martin (1983). This dimension embraces the parenting behavior of support and acquiescence which promotes the autonomy and self-affirmation of the child. The authors highlighted that this aspect can be assessed by a continuum raging from parents with low responsiveness to parents with high responsiveness.

The Overvigilance factor (Factor III) and Impaired Limits factor (Factor V) retained in the analysis could be considered antagonist (at least theoretically). This antagonism could be supported by Demandingness dimension of the classical model of Maccoby and Martin. The Demandingness refers to parenting behaviors of supervision and discipline. However, factors III and V presented low correlations in this research. Overall, the results indicated that the theoretical model proposed by Maccoby and Martin (1993) is not identical to the model proposed by Young (2003). Besides, the Overvigilance factor and Impaired Limits factor seem to be two different dimensions that are not part of the same continuous.

Regarding the structure of the YPI, confirmatory factor analysis presented adequate goodness of fit indices. The estimation of three covariances between errors terms improved the fit indices. For the invariance analysis, it was expected that the imposed restrictions (fixed parameters) to the models might reduce the goodness of fit. However, the variations observed until model 3 (fixed intercepts) were small. Considering that two random subsamples were evaluated, such results indicate that, at least, the structure and the factorial loadings remain invariant. In other words, the five factors structure was confirmed in different subsamples, therefore supporting the stability of the model.

The nine factor model proposed by Sheffield et al. (2005) showed a better fit to the data collected in this study than the original model (theoretically proposed), although the results did not indicate a sufficient fit to the model. The model proposed in the present research also represents significative improvement compared to previous model (Sheffield et al., 2005; Young, 2003). In this sense, the five factor model seams more parsimonious and accurate to assess and to comprehend the parenting styles in the Brazilian context.

Referring to convergent validity, the YPI and the Familiogram (FG) presented moderate correlations among some factors. The major associations between Family Conflict (FG) and Disconnection (YPI), as well between
Affectivity (FG) and Emotional Stability (YPI), indicated that the factors assess similar dimensions. However, is not possible to conclude that the YPI has convergent validity with FG, once the correlations were not strong enough. Nevertheless, it is important to highlight that the YPI aims to assess the cognitive representations of parenting style during the childhood and adolescence, while the FG aims to evaluate the current relationships between dyads. New studies, using other instruments, could improve the evidence of the convergent validity of the YPI scores.

Overall, the results of this study support the conclusion that the reduced version of Young Parenting Inventory adapted to Brazil presents evidence of the content and construct validity. In this sense, confirmatory factor analysis indicated that the five factor model presented in this study shows a better fit to the data than the previous models. In other words, the original structure was redesigned to fit the Brazilian context. Therefore, the proposed structure is adequate for future studies in Brazil. These future studies may be especially useful for family clinic.

\section{References}

Baptista, M. N., \& Oliveira, A. A. (2004). Sintomatologia de depressão e suporte familiar em adolescentes: Um estudo de correlação. Revista Brasileira de Crescimento e Desenvolvimento Humano, 14(3), 58-67.

Baumrind, D. (1966). Effects of authoritative parental control on child behavior. Child Development, 37(4), 887-907. doi: $10.2307 / 1126611$

Byrne, B. M. (2010). Structural equation modeling with AMOS: Basic concepts, applications, and programming (2nd ed.). New York, NY: Routledge.

Cecconello, A. M., De Antoni, C., \& Koller, S. H. (2003). Práticas educativas, estilos parentais e abuso físico no contexto familiar. Psicologia em Estudo, 8(No Spe.), 45-54. doi:10.1590/S1413-73722003000300007

Cohen, E., Sade, M., Benarroch, F., Pollak, Y., \& Gross-Tsur, V. (2008). Locus of control, perceived parenting style, and symptoms of anxiety and depression in children with Tourette's syndrome. European Child \& Adolescent Psychiatry, 17(5),299-305. doi:10.1007/s00787-007-0671-7

Darling, N., \& Steinberg, L. (1993). Parenting style as context: An integrative model. Psychological Bulletin, 113(3), 487496. doi:10.1037/0033-2909.113.3.487

Flouri, E. (2005). Psychological and sociological aspects of parenting and their relation to suicidal behavior. Archives of Suicide Research, 9(4), 373-383. doi:10.1080/13811110500182463

Hambleton, R. K. (1996). Adaptación de testes para su uso en diferentes idiomas y culturas: Fuentes de error, posibles soluciones y directrices prácticas. In J. Muñiz (Coord.), Psicometría (pp. 207-238). Madrid, España: Universitas.

Hernández-Nieto, R. (2002). Contribuciones al análisis estadístico. Mérida, Venezuela: Universidad de Los Andes. 
Hinrichsen, H., Sheffield, A., \& Waller, G. (2007). The role of parenting experiences in the development of social anxiety and agoraphobia in the eating disorders. Eating Behaviors, 8(3), 285-290. doi:10.1016/j.eatbeh.2006.11.003

Maccoby, E. E., \& Martin, J. A. (1983). Socialization in the context of the family: Parent-child interaction. In P. H. Mussen (Series Ed.), \& E. M. Hetherington (Vol. Ed.), Handbook of child psychology: Vol. 4. Socialization, personality, and social development (4th ed., pp. 1-101). New York, NY: Wiley.

Noie, Z., Farid, A. A., Fata, L., \& Ashoori, A. (2010). Comparison of early maladaptive schemas and their parental origins in OCD patients and non-clinical individuals. Advances in Cognitive Science, 12(1), 59-69.

Noronha, A. P. P., \& Alchieri, J. C. (2002). Reflexões sobre os instrumentos de avaliação psicológica. In R. Primi (Org.), Temas em avaliação psicológica (pp. 7-16). Campinas, SP: IBAP.

Noronha, A. P. P., \& Vendramini, C. M. M. (2003). Parâmetros psicométricos:Estudocomparativoentretestesdeinteligência e de personalidade. Psicologia: Reflexão e Crítica, 16(1), 177-182 . doi:10.1590/S0102-79722003000100018

O'Connor, B. P. (2000). SPSS and SAS programs for determining the number of components using parallel analysis and Velicer's MAP test. Behavior Research Methods, Instruments \& Computers, 32(3), 396-402. doi:10.3758/BF03200807

Pasquali, L. (2003). Psicometria: Teoria dos testes na psicologia e na educação. Petrópolis, RJ: Vozes.

Pilati, R., \& Laros, J. A. (2007). Modelos de equações estruturais em psicologia: Conceitos e aplicações. Psicologia: Teoria e Pesquisa, 23(2), 205-216. doi:10.1590/S0102-37722007000200011

Sheffield, A., Waller, G., Emanuelli, F., \& Murray, J. (2006). Is comorbidity in the eating disorders related to perceptions of parenting? Criterion validity of the revised Young Parenting Inventory. Eating Behaviors, 7(1), 37-45. doi:10.1016/j.eatbeh.2005.05.009

Sheffield, A., Waller, G., Emanuelli, F., Murray, J., \& Meyer, C. (2005). Links between parenting and core beliefs: Preliminary psychometric validation of the Young Parenting Inventory. Cognitive Therapy and Research, 29(6), 787-802. doi:10.1007/s10608-005-4291-6

Spera, C. (2005). A review of the relationship among parenting practices, parenting styles, and adolescent school achievement. Educational Psychology Review, 17(2), 125146. doi:10.1007/s10648-005-3950-1

Steinberg, L. (2001). We know some things: Parentadolescent relationships in retrospect and prospect. Journal of Research on Adolescence, 11(1), 1-19. doi:10.1111/1532-7795.00001

Teodoro, M. L. M. (2006). Afetividade e conflito em díades familiares: Avaliação com o familiograma. Revista Interamericana de Psicologia, 40(3), 385-390.
Van Vlierberghe, L., Timbremont, B., Braet, C., \& Basile, B. (2007). Parental schemas in youngsters referred for antisocial behaviour problems demonstrating depressive symptoms. Journal of Forensic Psychiatry \& Psychology, 18(4), 515-533. doi:10.1080/14789940701515442

Weber, L. N. D., Brandenburg, O. J., \& Viezzer, A. P. (2003). A relação entre o estilo parental e o otimismo da criança. Psico-USF, 8(1), 71-79.

Young, J. E. (1999). Young Parenting Inventory (YPI). Retrieved from http://www.schematherapy.com/id205.htm

Young, J. E. (2003). Terapia cognitiva para transtornos da personalidade: Uma abordagem focada em esquemas (M. A. V. Veronese, Trad., 3nd ed.). Porto Alegre, RS: Artmed. Young, J. E., Klosko, J. S., \& Weishaar, M. E. (2003). Schema therapy: A practitioner's guide. New York, NY: Guilford.

Zimmermann, J. J., Eisemann, M. R., \& Fleck, M. P. (2008). Is parental rearing an associated factor of quality of life in adulthood? Quality of Life Research: An International Journal of Quality of Life Aspects of Treatment, Care and Rehabilitation, 17(2), 249-255. doi:10.1007/s11136-007-9261-x

Felipe Valentini is a postdoctoral researcher at the Universidade Salgado de Oliveira.

João Carlos Alchieri is an Associate Professor at the Universidade Federal do Rio Grande do Norte.

Jacob Arie Laros is an Associate Professor at the Universidade de Brasília.

Received: Mar. $8^{\text {th }} 2012$

$1^{\text {st }}$ Revision: May $30^{\text {th }} 2013$

Approved: Jul. 10 2013

How to cite this article:

Valentini, F., Alchieri, J. C., \& Laros, J. A. (2013). Validity evidence for the reduced version of the Young Parenting Inventory (YPI). Paidéia (Ribeirão Preto), 23(56), 293-300. doi:10.1590/1982-43272356201303 